\title{
Impact of relative humidity and water availability on the life history of the predatory mite Amblyseius swirskii
}

Phyu Phyu San ( $\nabla$ phyuphyusan@yau.edu.mm )

Kyushu University

Midori Tuda ( $\square$ tuda@grt.kyushu-u.ac.jp )

Kyushu University https://orcid.org/0000-0001-8727-7181

Masami Takagi

Kyushu University

\section{Research Article}

Keywords: Predatory mite, Survival, Fecundity, Relative humidity, Intrinsic rate of increase, Water supply

Posted Date: March 3rd, 2021

DOI: https://doi.org/10.21203/rs.3.rs-218829/v2

License: (c) (i) This work is licensed under a Creative Commons Attribution 4.0 International License.

Read Full License 


\title{
Impact of relative humidity and water availability on the life history of the predatory mite Amblyseius swirskii
}

\author{
Phyu Phyu San ${ }^{a, c^{*}} \cdot$ Midori Tuda $^{a, b^{*}} \cdot$ Masami Takagi $^{a, b}$ \\ ${ }^{a}$ Laboratory of Insect Natural Enemies, Graduate School of Bioresource and Bioenvironmental Sciences, Kyushu \\ University, Fukuoka, Japan \\ ' Institute of Biological Control, Faculty of Agriculture, Kyushu University, Fukuoka, Japan \\ 'Department of Entomology and Zoology, Yezin Agricultural University, Naypyitaw, Myanmar
}

*Corresponding authors: Phyu Phyu San and Midori Tuda

Email Address: phyuphyusan@yau.edu.mm (P.P. San), tuda@grt.kyushu-u.ac.jp (M. Tuda)

\begin{abstract}
The predatory mite Amblyseius swirskii (Athias-Henriot) (Acari: Phytoseiidae) is currently used as an efficient biological control agent of thrips, whiteflies and spider mites, which are economically damaging pests of ornamental plants and vegetable crops grown in greenhouses and fields worldwide. Currently, the effects of relative humidity (RH) and water availability on the optimal growth of $A$. swirskii are unknown. Here, we test the combined effects of different levels of $\mathrm{RH}(33 \%, 53 \%, 73 \%$ and $92 \%)$ and water availability on the development and reproduction of male and female $A$. swirskii feeding on the dried fruit mite, Carpoglyphus lactis (Linnaeus). While eggs failed to hatch at 33\% RH, the survival rates of the immature stages at $\geq 53 \% \mathrm{RH}$ increased solely in response to water availability and not due to changes in RH. Regarding growth and development, low RH extended the egg-adult duration and pre-oviposition period. We also found that the negative effects of low RH on fecundity were partially or completely eliminated when drinking water was available. For the life table parameters, the highest values of net reproductive rate $\left(R_{0}\right)$ and intrinsic rate of natural increase $(r)$ were achieved at the highest RH and when drinking water was available. Overall, water availability mitigated the negative effect of low RH on female reproduction, and female development was more sensitive to water availability than male development.
\end{abstract}


Lastly, a comparison of similar research on A. swirskii suggested that water availability and RH are more influential on $r$ than food source or temperature.

Keywords Predatory mite $\bullet$ Survival $\bullet$ Fecundity $\bullet$ Relative humidity $\bullet$ Intrinsic rate of increase $\bullet$ Water supply

\section{Introduction}

The predatory mite Amblyseius swirskii (Athias-Henriot) (Acari: Phytoseiidae) is used worldwide as an effective biological control agent of whiteflies, thrips and spider mites on greenhouse crops such as sweet pepper, cucumber and ornamental plants (El-Laithy and Fouly 1992; Momen and El-Saway 1993; Messelink et al. 2008; Kim et al. 2009; Calvo et al. 2011). Commercially available since 2005, A. swirskii originates from the eastern Mediterranean region and is recognized as a generalist predator that feeds on a variety of insects and mites as well as on pollen and plant exudates (McMurtry and Croft 1997). Stored product mites are used as an alternative source of prey in the mass rearing of A. swirskii (Bolckmans and van Houten 2006). Following release, it is important that $A$. swirskii successfully colonize the introduced area in order to control the target pest. Understanding the effects of climate on predatory mites helps to predict their suitability in a release area, and this is particularly important for non-native species. In a given environment, the investigation of life history parameters is critical in evaluating the potential population growth of a species (Birch 1948). Temperature is typically a major driver of population growth in poikilothermic animals (Frazier et al. 2006), and relative humidity (RH) can constrain population growth at optimal temperatures, especially if the animal expends energy balancing hydration at the expense of reproduction (Colloff 2009). Therefore, the subsistence of predatory mites is influenced by the surrounding environment, temperature and RH, all of which are crucial for survival (Helle and Sabelis 1985; Ghazy et al. 2016). Since the initial discovery of A. swirskii, however, most studies have focused on aspects of its development and potential effects in biological control under a limited range of temperatures and RHs, apart from a single study of temperature-dependent life history parameters (Lee and Gillespie 2011).

To preserve physiological integrity, predatory mites need to maintain an adequate level of body water (twothirds of body mass, Yoder 1998) within tolerable limits (Wharton 1985; Hadley 1994). However, water conservation is a major challenge due to their small size $(0.2-0.5 \mathrm{~mm}$ in length); predatory mites lose water during respiration, by diffusion across the surface of the body and through the secretion of digestive fluids and 
reproductive products as well as during oviposition and excretion (Arlian and Veselica 1979). Therefore, the successful release and colonization of predatory mites may be influenced by the RH of the target area (Fatnassi et al. 2015; Shimoda et al. 2019). Species and strains of predatory mites that originate from different geographical regions exhibit varying responses to $\mathrm{RH}$. The effects of RH on the biology of other phytoseiid predatory mites have been noted [egg hatching success of Euseius finlandicus (Oudemans), Typhlodromus pyri Scheuten and Kampimodromus aberrans (Oudemans) (Schausberger 1998; Ferrero et al. 2010); development and longevity of $A$. alstoniae Gupta (Kumari and Sadana 1991); development and mortality of T. aripo De Leon (Mutisya et al. 2010); development and life table of A. largoensis (Muma) (Gómez-Moya et al. 2018)]. In A. swirskii, however, the effects of RH on life history have received little attention.

Predatory mites are not only affected by RH, but by the availability of drinking water as well (Dinh et al. 1988). Water is of major importance to all living things, including those with applications to biological control (Tuda et al. 2006; Tuda 2011). For predatory mites, the availability of free water increases the survival of the immature stages of Amblydromalus limonicus (Garman \& McGregor) (Liu and Zhang 2017) and the overall survival of Iphiseius degenerans (Berlese), Neoseiulus cucumeris (Oudemans), N. californicus (McGregor) and Phytoseiulus persimilis Athias-Henriot (Williams et al. 2004). Furthermore, transpiration rates (water loss) differ between male and female mites (Arlian 1975; Lavadinho 1975). However, the sex-specific effects of RH and water availability on A. swirskii are currently unknown. In the present study, we investigate the life history of male and female A. swirskii under different levels of RH and water availability in laboratory conditions.

\section{Materials and methods}

Predatory mite culture

The predatory mite A. swirskii (Israeli strain) and its prey, the dried fruit mite Carpoglyphus lactis (Linnaeus), were obtained from Arysta LifeScience Cooperation (Tokyo, Japan). The predators were enclosed in a ventilated plastic container $(9 \mathrm{~cm}$ diameter $\times 4 \mathrm{~cm}$ height $)$ provisioned with dried fruit mites. The dried fruit mites were supplied with a diet of baker's yeast, following San et al. (2020). The predatory mite cultures were inspected once a week, and fresh diet was added as needed to maintain a healthy stock of dried fruit mites. If fungi developed on the culture over time, both mite species were transferred to a new container with fresh food. The lids of the containers were coated with Parafilm to prevent the mites from escaping. All colonies were kept in an incubator at $25{ }^{\circ} \mathrm{C}, 70 \%$ 
$\mathrm{RH}$ and a $16 \mathrm{~h}$ light: $8 \mathrm{~h}$ dark photoperiod. We chose this temperature because, while $A$. swirskii can develop and reproduce between $15-36^{\circ} \mathrm{C}$, its net reproduction is highest at $25^{\circ} \mathrm{C}$ (Lee and Gillespie 2011).

\section{Experimental conditions}

The experiment was conducted at 33\%, 53\%, 73\% and 92\% RH in a climate-controlled chamber held at $25{ }^{\circ} \mathrm{C}$ with a 16:8 light:dark photoperiod. To maintain a constant $\mathrm{RH}$, sealed plastic containers $(32 \times 23 \times 10 \mathrm{~cm})$ were filled with an appropriate saturated salt solution $(300 \mathrm{ml}) ; \mathrm{MgCl}_{2} .6 \mathrm{H}_{2} \mathrm{O}, \mathrm{Mg}\left(\mathrm{NO}_{3}\right)_{2} .6 \mathrm{H}_{2} \mathrm{O}, \mathrm{NaAc} 3 \mathrm{H}_{2} \mathrm{O}$ and $\mathrm{Na}_{2} \mathrm{C}_{4} \mathrm{H}_{4} \mathrm{O}_{6}$ were used for the 33\%, 53\%, 73\% and 92\% RH treatments, respectively (Winston and Bates 1960). A plastic stage $(31 \times 21 \times 3 \mathrm{~cm})$ was placed above the surface of the salt solution to be used as a platform for the petri dishes that housed the experimental mites. RH was recorded whenever data were collected (twice per day during the immature stages and once per day during the adult stage) with a calibrated hygrometer (Crecer, Sanmu, Japan) that was kept in the container.

\section{Development, reproduction and life table}

For the experiment, gravid adult females from the stock cultures were kept in petri dishes to lay eggs at $25{ }^{\circ} \mathrm{C}$ and $70 \%$ RH. Newly laid eggs ( $<12 \mathrm{~h}$ old) were transferred singly using a fine camel-hair brush into the plastic petri dishes $(9 \mathrm{~cm}$ diameter, one egg per petri dish) used in the experiment. Each petri dish contained a piece of filter paper $(3.8 \times 6.0 \mathrm{~cm})$ covered by two pieces of black polyvinyl chloride tape $(1.9 \times 7.0 \mathrm{~cm}$ each $)$, forming a 'plate' on which the mites were located. The two strips of black tape were oriented side-by-side so that there was a very narrow gap between the two pieces; in treatments where drinking water was available to the mites, this small gap prevented the water from evaporating (Fig. 1). For the treatments with drinking water, about $40 \mu \mathrm{l}$ of water was added every day to one side of filter paper, and the mites had free access to this water from the larval stage until death. A small piece of plastic (referred to as a 'shelter') was provided as a resting and oviposition site. To prevent the mites from escaping the plate, the periphery of the plate was coated with axle grease (Gillespie et al. 2000). These petri dishes were subsequently maintained inside relative humidity-controlled containers (25 petri dishes per container) prepared for four different levels of RH (33\%, 53\%, 73\% and 92\% RH). Seventy-five individual eggs - 25 eggs with drinking water (W) and 50 eggs without water (NW, 'no water') - were tested for each RH. Greater numbers of eggs were prepared for the NW treatments because higher mortality was expected. 
The duration of each developmental stage (egg, larva, protonymph and deutonymph) was recorded every $12 \mathrm{~h}$ until the adult stage was reached. After adult emergence, observations were taken every $24 \mathrm{~h}$ until the mite died. During each observation we monitored developmental duration, survival, fecundity and adult longevity. All predatory mites were offered about 15 dried fruit mites as a food source at each observation period. The presence of exuviae on the plate was used to determine whether each mite successfully molted to the next developmental stage. Each newly emerged adult female was individually paired with a male on a new plate in a petri dish. Since more females emerged than males, additional male mites were prepared separately (in the same RH as the females) to supplement the number of emerging males. Preoviposition duration, oviposition duration and daily oviposition rate were recorded for each adult female. The eggs laid by each female were maintained under the same RH as the parents to test the effects of RH on the sex ratio of the offspring. Adult mites were sexed based on their body size and morphology; females are larger than males and possess a large, swollen abdomen.

The survival and reproduction data collected during the experiment were combined to construct age-specific (cohort) life tables for A. swirskii. The intrinsic rate of natural increase $(r)$, net reproductive rate $\left(R_{0}=\sum l_{x} m_{x}\right.$, the number of female offspring produced per female), mean generation time (the period between the birth of the parent and that of the offspring), finite rate of increase ( $\lambda=e^{r}$, the population multiplication factor for a unit of time) and gross reproduction rate (GRR $=\sum m_{x}$, the average number of female offspring produced by a group of females) were calculated according to Chi and Liu (1985) and Chi (1988) using the computer program TWOSEX-MS Chart (Chi 2020). Standard errors of life table parameters were obtained using bootstrap technique, and multiple comparisons were done by the paired bootstrap test, with 100,000 samplings.

\section{Statistical analysis}

The effects of RH, water availability and sex, and their interactions on the developmental durations of the immature stages, adult longevity, preoviposition and oviposition periods were analyzed using a parametric survival analysis with the best fit distribution (Weibull, log-normal, exponential, Frechet or log-logistic). If a three-way interaction was not significant, we excluded it from the model and repeated the analysis with the reduced model. The effects of RH and water availability and their interaction on fecundity were analyzed using generalized linear models with a Poisson distribution and a log link function; the effects of these same variables on stage-wise survival rates and on 
the sex ratio of the offspring were analyzed using logistic regression with a logit link function. If overdispersion of the data was significant, it was incorporated in the model. Significant factors were then subjected to post-hoc multiple comparison tests with a Holm-Bonferroni sequential correction (Holm 1979). After confirming the normality of the data distribution, oviposition rate was analyzed using a general linear model followed by a Tukeytype post-hoc test. For values of $r$ collected from the literature and this study, a generalized linear model was used to test the relative effects of $\mathrm{RH}$, water availability, temperature and food source with a normal distribution and a $\log$ link function as well as the interaction between RH and temperature. A post-hoc multiple comparison test with a Holm-Bonferroni sequential correction was performed to compare $r$ among the different food sources (mites, whiteflies, pollen, prey mixed with pollen and artificial diets). Significance levels for all tests were set at $P=0.05$. All statistical tests were carried out using JMP (ver. 13.2.1).

\section{Results}

Development and adult longevity

Eggs did not hatch at the lowest RH (33\%), thus this treatment was excluded from subsequent analyses. The development period of $A$. swirskii was influenced by RH, water availability and sex (Supplementary table S1). Egg duration was significantly longer at 53\% RH than at $92 \% \mathrm{RH}$ (Weibull distribution, Supplementary table S2).

The larval development period was affected by water availability and by the interaction between RH and sex (log-normal distribution, Supplementary table S1). The larval duration was longer when water was available than when water was not available (Supplementary table S2). For the $\mathrm{RH} \times$ sex interaction, female larvae developed faster at $92 \% \mathrm{RH}$ than at $73 \% \mathrm{RH}$, whereas the development period of male larvae was unaffected by $\mathrm{RH}$ (Supplementary table S2). The duration of the protonymph stage was affected by water availability and the interaction between RH and water availability (Supplementary table S1). The protonymph stage was longer when water was unavailable compared to when water was available (log-logistic distribution, Supplementary table S2). For the interaction between RH and water availability, no significant pairwise differences in protonymph duration were detected by multiple comparison tests. The duration of the deutonymph stage was affected by water availability, sex and the interaction between RH and water availability (log-logistic distribution, Supplementary table S1). The deutonymph stage was shortened at 53\% RH when water was available and was longer for females than for males (Supplementary table S2). The deutonymph duration was shorter at 53\% and $73 \%$ RH with water and at $92 \%$ RH with no water than at 53\% RH with no water (Supplementary table S2). 
The overall development time from egg to adult was affected by RH as well as the interactions between RH and water availability, water availability and sex, and RH and sex (Frechet distribution, Supplementary table S1). Egg to adult duration was significantly shorter at $92 \% \mathrm{RH}$ than at $53 \%$ and $73 \% \mathrm{RH}$. For the $\mathrm{RH} \times$ sex interaction, the egg-adult period was shorter at $92 \% \mathrm{RH}$ than at $53 \%$ and $73 \% \mathrm{RH}$ for females, and shorter at $92 \% \mathrm{RH}$ than at $53 \% \mathrm{RH}$ for males (Table 1). For the water availability $\times$ sex interaction, the egg-adult duration of females provided with water was shorter than when water was unavailable, whereas male development was not affected by water availability (Table 1 ). For the $\mathrm{RH} \times$ water availability interaction, the egg-adult duration at $92 \% \mathrm{RH}$ regardless of water availability was shorter than at $53 \%$ and $73 \%$ RH with no water (Table 1 ).

The adult longevity of $A$. swirskii was affected by sex and the interaction between RH and water availability (log-normal distribution, Supplementary table S1). Females lived significantly longer than males (Table 1). Multiple comparison tests on the interaction between RH and water availability did not detect any significant pairwise differences.

\section{Reproductive parameters}

All reproductive parameters of female $A$. swirskii were affected by RH and water availability (Table 2), with the exception of oviposition period (Weibull distribution, Supplementary table S1). At 53\% and $73 \% \mathrm{RH}$, females had a longer preoviposition period when water was unavailable compared to when water was available; however, water availability did not affect the preoviposition period at 92\% RH (Frechet distribution, Fig. 2a). At 53\% and 73\% RH, mites provided with water had a higher fecundity, which increased with increasing RH (Fig. 2b). At 92\% RH, fecundity was unaffected by water availability but was as high as at $73 \% \mathrm{RH}$ when water was available (Fig. 2b). Overall, oviposition rate increased with increasing RH (Fig. 2c) and with access to drinking water (Fig. 2d).

Age-specific survival and fecundity, and stage-wise survival

Except for at 33\% RH, all eggs hatched regardless of RH. Overall survivorship was affected by water availability, and survival rates were higher with water for the larval, protonymph and immature (i.e., egg-adult) stages [0.95 \pm $0.01,0.94 \pm 0.02$ and $0.80 \pm 0.02$ with water, and $0.80 \pm 0.03,0.76 \pm 0.01$ and $0.47 \pm 0.05$ (mean $\pm \mathrm{SE}$ ) without water for each stage; Table 2]. Patterns in the age-specific survival $\left(l_{x}\right)$ and age-specific fecundities $\left(m_{x}\right)$ of $A$. swirskii varied depending on water availability, but were generally similar at 53\%, 73\% and 92\% RH (Fig. 3). When A. swirskii did not have access to drinking water, the survival curves sharply decreased during the younger 
life stages, which meant that mortality was higher for the immature stages than it was for adults. When water was available, the survival curves indicated moderate mortality rates throughout life. For age-specific fecundity, newly hatched females without access to water started laying eggs after 7 to 9 days, while those that were provided with water began laying eggs after 6 to 7 days. Peak oviposition occurred during the early oviposition period, after which time egg production gradually decreased across all treatments, with the exception of several peak oviposition periods that occurred at $73 \% \mathrm{RH}$ when water was available. The highest peak oviposition was observed at $92 \% \mathrm{RH}$ when water was available (2.34 eggs, 13 days after egg hatching), and the second highest peak was at 92\% RH when water was unavailable (1.53 eggs, 12 days after egg hatching).

\section{Life table parameters and sex ratio}

$R_{0}, r$ and $\lambda$ were higher when water was available and increased with increasing $\mathrm{RH}$ especially when water was unavailable (Table 3). The mean generation time was shorter with increasing RH and access to free water. All life table parameters for the predatory mites were better when water was available. The sex ratio of the offspring was affected by $\mathrm{RH}$ (Table 2) and was higher at $92 \% \mathrm{RH}$ (female ratio, $0.831 \pm 0.021$, mean \pm SE) than at $73 \%$ $\mathrm{RH}(0.683 \pm 0.034)$, but both were not significantly different from the sex ratio at $53 \% \mathrm{RH}(0.712 \pm 0.046)$. Water availability did not affect the sex ratio (Table 2).

$\mathrm{RH}$, water availability and intrinsic rate of increase $(r)$

Our analysis of $r$ for A. swirskii (Table 4) indicated that RH (range 33-92\%, $\chi^{2}{ }_{1}=11.96, P=0.0005$ ) and water availability $\left(\chi^{2}{ }_{1}=7.60, P=0.0058\right)$ may be more influential to $r$ than food source $\left(\chi^{2}{ }_{4}=13.16, P=0.0105\right)$ or temperature (range $13-36^{\circ} \mathrm{C}, \chi^{2}{ }_{1}=5.27, P=0.0216$ ) after excluding the non-significant $\mathrm{RH} \times$ temperature interaction $\left(\chi^{2}{ }_{1}=0.01, P=0.931\right)$. The intrinsic rate of increase $r$ was significantly higher when $A$. swirskii preyed on whiteflies than when feeding on pollen. Intermediate values of $r$ were observed when A. swirskii was provided with mites, a mixed diet (pollen and prey) or an artificial diet, but these values of $r$ were not significantly different from those on whiteflies or pollen.

\section{Discussion}

The immature developmental stages of $A$. swirskii can be completed at as low as $53 \% \mathrm{RH}$, potentially due to a reduction in water loss through the integument or during respiration (Hadley 1994), and reproduction can occur 
successfully from $53-92 \% \mathrm{RH}$ at $25{ }^{\circ} \mathrm{C}$. The tolerance for RH and survival ability of phytoseiid mites are dependent upon their original climate (Dinh et al. 1988). Species of predatory mites that predominately inhabit pantropical regions, which have long rainy seasons, are likely able to complete their development at or above $80 \%$ RH (Gómez-Moya et al. 2018). However, A. swirskii inhabits relatively dry geographic areas in the Mediterranean, and phytoseiid mites from dry areas are more resistant to low RH than species from humid areas (McMurtry et al. 1976; McMurtry 1980). Adaptations to dry conditions may include morphological traits, physiological processes, and behavioral traits (Swift and Blaustein 1980; Perring and Lackey 1989; Gaede 1992).

Development and adult longevity

The development times of the different immature stages of A. swirskii varied based on RH, water availability and sex. Morphological variation is linked to differences in biochemical, metabolic, and physiological processes (Freriksen et al. 1994). A number of studies have found that the developmental duration of some predatory mites is shortened by high RH (Rivard 1961; Ustchekow and Begljarow 1968; Stenseth 1979; Walzer et al. 2007), with few exceptions (Mutisya et al. 2010). In A. swirskii, higher developmental rates were achieved for females by providing drinking water. Invertebrate development is influenced by the surrounding RH via many physiological processes in addition to water loss from body surfaces (Buxton 1932) and the availability of drinking water (Mellanby 1958).

\section{Reproductive parameters}

Except for at $33 \% \mathrm{RH}$, fecundity was optimal at all RH levels if drinking water was available and at $92 \% \mathrm{RH}$ regardless of water availability (Fig. 2b). Thus, the availability of drinking water is remarkably important for the predator's reproduction, particularly under low RH conditions. But under high water vapor saturation (92\% RH), the predatory mites did not require drinking water to lay more eggs. Some arthropods possess an active sorption mechanism by which an adequate amount of water is extracted from the subsaturated atmosphere to compensate for water loss (Nobel-Nesbitt 1969; Wharton and Devine 1968; Arlian 1975).

The oviposition rate considerably increased with higher levels of RH and water availability. Analysis of the reproductive parameters suggests that, while $73 \% \mathrm{RH}$ might allow for a steady population increase over a relatively long period of time, $92 \% \mathrm{RH}$ promotes a rapid population surge within a short period of time. The predatory mite A. swirskii prefers to lay eggs at high RH and shows a strong hygropreference for reproduction. Because of the 
short preoviposition period and high fecundity of $A$. swirskii, population increases will be higher under moist conditions.

Age-specific survival, fecundity and stage-wise survival

The availability of drinking water is important for the survival of immature predatory mites irrespective of RH (Fig. 3). There is some evidence that water availability increases survival in other species of predatory mites (Blommers et al. 1977; Sabelis 1981; Dinh et al. 1988). The age-specific survival curves represent a type-III survivorship pattern, following the classification method of Demetrius (1978).

Eggs are most vulnerable to low RH levels (Sabelis 1981) because this stage is unable to compensate for water loss by feeding on prey or drinking water (Dinh et al. 1988; Bakker et al. 1993; Walzer et al. 2007). Even though the eggs of A. swirskii failed to hatch at $33 \% \mathrm{RH}, 100 \%$ hatched at $53 \% \mathrm{RH}$, which is higher compared to other phytoseiid mites; for example, I. degenerans, N. cucumeris, N. californicus and P. persimilis all have poor hatchability at 50-60\% RH (Williams et al. 2004).

\section{Sex differences}

Female A. swirskii larvae developed faster at the highest level of RH $(92 \% \mathrm{RH})$, whereas the development of male larvae was not affected by RH. Male deutonymphs developed faster than females. While the availability of water decreased the egg-adult development time for females, the male egg-adult period was unaffected by water availability. Overall, females lived longer than males likely due to their larger body size and that they are regulated by different physiological activities and norms (Wigglesworth 1942; Fischer and Fiedler 2000).

Life table parameters and sex ratio

Of the RH regimes at $25{ }^{\circ} \mathrm{C}$, the fastest population increase (the maximum values of $R_{0}$ and $r$ ) of $A$. swirskii occurred at $92 \%$ RH when drinking water was present. High RH and water availability clearly affected the developmental duration, survival and fecundity of $A$. swirskii, which in turn had a positive effect on fitness. The sex ratio of the offspring of a single female tends to be inconsistent (Boudreaux 1963) and varies based on the abundance of consumed prey and by the number of progeny (Abou-Awad and Reda 1992; Toyoshima and Amano 1998), but is not influenced by disturbances during mating or the age of mating females (Saber and Momen 2000). A highly female-biased sex ratio under high RH will enhance the growth rate of a population (Southwood et al. 1974). 
$\mathrm{RH}$, water availability and intrinsic rate of increase $(r)$

Our review and analysis of $r$ estimated that the effects of water availability and RH are relatively more important than food source and temperature on the intrinsic rate of increase for A. swirskii. Regarding food sources, our analysis indicated that when A. swirskii feeds solely on the spider mite Tetranychus urticae (El-Laithy and Fouly 1992; Riahi et al. 2017), T. urticae together with pollen (Riahi et al. 2017) or on an artificial diet (Nguyen et al. 2013), the $r$ values are similar to those when feeding on dried fruit mites (this study) at similar RHs, but when $A$. swirskii feeds on the whitefly Bemisia tabaci (Nomikou et al. 2001), $r$ increases with no statistical significance. Higher RH and water availability should improve $r$ whenever any of these food sources are utilized. However, if high RH affects the availability of the food source, then this prediction may not apply (San et al. 2020). Overall, whiteflies may be the best source of food for A. swirskii, but fruit mites are just as effective as other species of mites, artificial diets and mixed diets of mites and pollen.

Temperature, however, might affect life history traits of predatory mites at unfavorable RHs; for example, while $84 \%$ of $P$. persimilis eggs hatch at $40 \%$ RH and $21{ }^{\circ} \mathrm{C}$, only $8 \%$ of eggs hatch at $27{ }^{\circ} \mathrm{C}$ (Stenseth 1979). In general, the development of female A. swirskii is more sensitive to water availability than the development of males. The highest intrinsic rate of increase was achieved when water was available at the highest RH, and the availability of drinking water mitigated the negative effects of low RH on female reproduction. Based on this study, A. swirskii should be capable of colonizing habitats that have a moist microclimate and available drinking water. Currently, A. swirskii is often recommended for controlling thrips and whiteflies in greenhouses or field crops, particularly at temperatures above $30^{\circ} \mathrm{C}$. In comparison with $N$. cucumeris, A. swirskii provides better control of thrips during the summer, especially in temperate regions, whereas both have a similar efficacy during the winter (Buitenhuis et al. 2015). The optimal temperature range of both predators is between $20-32{ }^{\circ} \mathrm{C}$ (Cloutier et al. 1995; Lee and Gillespie 2011); however, the recommended production temperature in greenhouses usually falls between $17-25^{\circ} \mathrm{C}$ (Shipp et al. 1996). Additionally, the feeding rate of A. swirskii is higher under short day lengths (or even complete darkness) than it is under long day lengths (Yousef et al. 1982), which explains the occurrence of A. swirskii on the lower surfaces of leaves during the day.

The potential application of phytoseiid mites depends on providing a suitable environment for the agent (Ghazy et al. 2016). By understanding the effects of water availability and RH on A. swirskii population growth, this knowledge can be used to outline effective rearing conditions. Under greenhouse conditions, diurnal cycles in 
temperatures, RH and light intensity can influence pests and biocontrol agents directly or indirectly, with the indirect effects mediated by induced changes in the host plants. Moreover, because of their diminutive size, even small changes in the microenvironmental conditions at the leaf's surface can affect the biology of plant-dwelling mites. For example, RH levels around the leaf layer (within $0.5-5.0 \mathrm{~mm}$ ) are slightly higher than ambient due to leaf transpiration (Shipp et al. 2009). Finally, to predict the suitability of this mite for augmentative release in a particular field or greenhouse (Shimoda et al. 2019), future experiments should investigate the effects of changes in temperature, $\mathrm{RH}$ and photoperiod throughout the entire growing season of the host plants.

\section{Acknowledgements}

SPP thank Japan International Cooperation Center (JICE) for providing financial support. MT was supported by Kyushu University. We thank J. Miksanek for comments.

\section{Contributions}

Phyu Phyu San: conceptualization, methodology, investigation, formal analysis, writing - original draft preparation. Midori Tuda: conceptualization, methodology, formal analysis, writing - reviewing and editing, supervision. Masami Takagi: conceptualization, supervision.

\section{Conflict of interest}

The authors declare that there are no conflicts of interest associated with this publication.

\section{References}

Abou-Awad BA, Reda AS (1992) Studies on copulation, egg production and sex-ratio of the predaceous mite Agistemus exsertus Gonzalez (Acari: Stigmaeidae). J Appl Ent 113:472-475

Arlian LG (1975) Dehydration and survival of the European house dust mite, Dermatophagoides pteronyssinus. J Med Ent 12:437- 444

Arlian LG, Veselica MM (1979) Water balance in insects and mites. Comp Biochem Physiol A 64:191-200

Bakker FM, Klein ME, Mesa NC, Braun AR (1993) Saturation deficit tolerance spectra of phytophagous mites and their phytoseiid predators on cassava. Exp Appl Acarol 17:97-113

Bazgir F, Shakarami J, Jafari S (2018) Life table and predation rate of Amblyseius swirskii (Acari: Phytoseiidae) fed on Eotetranychus frosti (Tetranychidae) and Cenopalpus irani (Tenuipalpidae). Syst Appl Acarol 23:1614-1626

Birch LC (1948) The intrinsic rate of natural increase of an insect population. J Anim Ecol 17:15-26

Blommers L, Lobbes P, Vink P, Wegdam F (1977) Studies on the response of Amblyseius bibens (Acarina: Phytoseiidae) to condition of prey scarcity. Entomophaga 22:247-258

Bolckmans KJF, van Houten YM (2006) Mite composition, use thereof, method for rearing the phytoseiid predatory mite Amblyseius swirskii, rearing system for rearing said phytoseiid mite and methods for biological pest control on a crop. WO Patent WO/2006/057552

Boudreaux HB (1963) Biological aspects of some phytophagous mites. Annu Rev Entomol 8:137-154

Buitenhuis R, Murphy G, Shipp L, Scott-Dupree C (2015) Amblyseius swirskii in greenhouse production systems: a floriculture perspective. Exp Appl Acarol 65:451-464

Buxton PA (1932) Terrestrial insects and the humidity of the environment. Biol Revs, 7:275-320

Calvo FJ, Bolckmans K, Belda JE (2011) Control of Bemisia tabaci and Frankliniella occidentalis in cucumber by Amblyseius swirskii. BioControl 56:185-192

Chi $\mathrm{H}$ (1988) Life-table analysis incorporating both sexes and variable development rates among individuals. Environ Entomol 17:26-34 
Chi H (2020) TWOSEX-MSChart: a computer program for the age stage, two-sex life table analysis. National Chung Hsing University, Taichung, Taiwan. http://140.120.197.173/Ecology/Download/Twosex- MSChart.zip (accessed 8 January 2021)

Chi H, Liu H (1985) Two new methods for the study of insect population ecology. Bull Inst Zool Acad Sin 24:225-240

Cloutier C, Arodokoun D, Johnson SG, Gelinas L (1995) Thermal dependence of Amblyseius cucumeris (Acarina: Phytoseiidae) and Orius insidiosus (Heteroptera: Anthocoridae) in greenhouses. In: Parker BL, Skinner M, Lewis T (eds) Thrips biology and management. NATO ASI Series (Series A: Life Sciences), vol 276. Springer, Boston, MA, pp 231-235

Colloff MJ (2009) Dust mites. CSIRO Publishing and Springer Science, Dordrecht, The Netherlands.

Demetrius L (1978) Adaptive value, entropy and survivorship curves. Nature 275:213-214

Dinh NV, Sabelis MW, Janssen A (1988) Influence of humidity and water availability on the survival of Amblyseius idaeus and A. anonymus (Acarina: Phytoseiidae). Exp Appl Acarol 4:27-40

El-Laithy AYM, Fouly AH (1992) Life table parameters of the two phytoseiid predators Amblyseius scutalis (AthiasHenriot) and A. swirskii A.-H. (Acari, Phytoseiidae) in Egypt. J Appl Entomol 113:8-12

Fatnassi H, El Arnaouty SA, Brun R, Pizzol J, Kortam M (2015) Dispersal and maintenance of Neoseiulus cucumeris Oudemans and Amblyseius swirskii Athias-Henriot (Acari: Phytoseiidae) to control Thrips in greenhouse crops as influenced by micro habitat environment. Egypt J Biol Pest Control 25:703-707

Ferrero M, Gigot C, Tixier MS, Van Houten YM, Kreiter S (2010) Egg hatching response to a range of air humidities for six species of predatory mites. Entomol Exp Appl 135:237-244

Fischer K, Fiedler K (2000) Sex-related differences in reaction norms in the butterfly Lycaena tityrus (Lepidoptera: Lycaenidae). Oikos 90:372-380

Frazier MR, Huey RB, Berrigan D (2006) Thermodynamics constrains the evolution of insect population growth rates: "Warmer is better". Am Nat 168:512-520

Freriksen A, Seykens D, Heinstra PWH (1994) Differences between larval and adult Drosophila in metabolic degradation of ethanol. Evolution 48:504-508

Gaede K (1992) On the water balance of Phytoseiulus persimilis A.-H. and its ecological significance. Exp Appl Acarol 15:181-198

Ghazy NA, Osakabe M, Negm MW, Schausberger P, Gotoh T, Amano H (2016) Phytoseiid mites under environmental stress. Biol Control 96:120-134

Gillespie DR, Opit G, Roitberg B (2000) Effects of temperature and relative humidity on development, reproduction, and predation in Feltiella acarisuga (Vallot) (Diptera: Cecidomyiidae). Biol Control 17:132-138

Gómez-Moya CA, Gondim MGC, de Moraes GJ, de Morais EGF (2018) Effect of relative humidity on the biology of the predatory mite Amblyseius largoensis (Acari: Phytoseiidae). Int J Acarol 44:400-411

Hadley NF (1994) Water relations of terrestrial arthropods. Academic Press, San Diego. pp 356

Helle W, Sabelis MW (1985) Spider mites. Their biology, natural enemies and control. World crop pests, vol 1B. Elsevier Science, Amsterdam. pp 458

Holm S (1979) A simple sequentially rejective multiple test procedure. Scand J Stat 6:65-70

Ji J, Lin T, Zhang YX, Lin JZ, Sun L, Chen X (2013) A comparison between Amblyseius (Typhlodromips) swirskii and Amblyseius eharai with Panonychus citri (Acari: Tetranychidae) as prey: developmental duration, life table and predation. Syst Appl Acarol 18:123-129

Kim T, Ahn J, Lee JH (2009) Temperature-dependent developmental model of Neoseiulus californicus (McGregor) (Acari, Phytoseiidae). J Appl Entomol 133:284-291

Kumari M, Sadana GL (1991) Influence of temperature and relative humidity on the development of Amblyseius alstoniae (Acari: Phytoseiidae). Exp Appl Acarol 11:199-203

Lavadinho AMP (1975) Variation of adult body weight in Sitophilus granarius (L.) from laboratory cultures. J Stored Prod Res 11:33-39.

Lee HS, Gillespie DR (2011) Life tables and development of Amblyseius swirskii (Acari: Phytoseiidae) at different temperatures. Exp Appl Acarol 53:17-27

Liu JF, Zhang ZQ (2017) Development, survival and reproduction of a New Zealand strain of Amblydromalus limonicus (Acari: Phytoseiidae) on Typha orientalis pollen, Ephestia kuehniella eggs, and an artificial diet. Int J Acarol 43:153-159

McMurtry JA (1980) Biosystematics of three taxa in the Amblyseius finlandicus group from South Africa, with comparative life history studies (Acari: Phytoseiidae). Int J Acarol 6:147-156

McMurtry JA, Croft BA (1997) Life-styles of phytoseiid mites and their roles in biological control. Annu Rev Entomol 42:291-321

McMurtry JA, Mahr DL, Johnson HG (1976) Geographic races in the predaceous mite, Amblyseius potentillae (Acari: Phytoseiidae). Int J Acarol 2:23-28

Mellanby K (1958) Water content and insect metabolism. Nature 181:1403

Messelink GJ, van Maanen R, van Steenpaal SEF, Janssen A (2008) Biological control of thrips and whiteflies by a shared predator: Two pests are better than one. Biol Control 44:372-379

Midthassel A, Leather SR, Baxter IH (2013) Life table parameters and capture success ratio studies of Typhlodromips swirskii (Acari: Phytoseiidae) to the factitious prey Suidasia medanensis (Acari: Suidasidae). Exp Appl Acarol 61:69-78 
Momen FM, Abdel-Khalek A (2008) Effect of the tomato rust mite Aculops lycopersici (Acari: Eriophyidae) on the development and reproduction of three predatory phytoseiid mites. Int J Trop Insect Sci 28:53-57

Momen FM, El-Saway SA (1993) Biology and feeding behaviour of the predatory mite, Amblyseius swirskii (Acari: Phytoseiidae). Acarologia 34:199-204

Mutisya DL, Kariuki CW, Khamala CPM (2010) Growth and development of the cassava predatory mite Typhlodromalus aripo (Acari: Phytoseiidae) under different relative humidity regimes. E Afr Agric For J 76:97-102

Nguyen DT, Vangansbeke D, Lü X, de Clercq P (2013) Development and reproduction of the predatory mite Amblyseius swirskii on artificial diets. BioControl 58:369-377

Nobel-Nesbitt J (1969) Water balance in the firebrat, Thermobia domestica (Packard). Exchanges of water with the atmosphere. J Exp Biol 50:745-769

Nomikou M, Janssen A, Schraag R, Sabelis MW (2001) Phytoseiid predators as potential biological control agents for Bemisia tabaci. Exp Appl Acarol 25:271-291

Park HH, Shipp L, Buitenhuis R, Ahn JJ (2011) Life history parameters of a commercially available Amblyseius swirskii (Acari: Phytoseiidae) fed on cattail (Typha latifolia) pollen and tomato russet mite (Aculops lycopersici). J Asia Pac Entomol 14:497-501

Perring TM, Lackey LJ (1989) Temperature and humidity effects on mortality and pre-adult development of two Phytoseiulus persimilis strains (Acari: Phytoseiidae). Int J Acarol 15:47-52

Riahi E, Fathipour Y, Talebi AA, Mehrabadi M (2017) Linking life table and consumption rate of Amblyseius swirskii (Acari: Phytoseiidae) in presence and absence of different pollens. Ann Entomol Soc Am 110:244-253

Rivard I (1961) Influence of temperature and humidity on mortality and rate of development of immature stages of the mite Tyrophagus putrescentiae (Schrank) (Acarina: Acaridae) reared on mold cultures. Can J Zool 39:419-426

Sabelis MW (1981) Biological control of two-spotted spider mites using phytoseiid predators. Part I: modelling the predator-prey interaction at the individual level. Agric Res Reports, Pudoc, Wageningen 238-242

Saber SA, Momen FM (2000) Effects of mating factors on reproduction and sex-ratio of the predacious mite Amblyseius zaheri Yous. and El-Bor. (Acari, Phytoseiidae). J Pest Sci 73:113-115

San PP, Tuda M, Nakahira K, Takagi M (2020) Optimal rearing medium for the population growth of the predatory mite, Amblyseius swirskii (Athias-Henriot) (Acari: Phytoseiidae). Egypt J Biol Pest Control 30:130

Schausberger P (1998) The influence of relative humidity on egg hatch in Euseius filandicus, Typhlodromus pyri and Kampimodromus aberrans (Acari, Phytoseiidae). J Appl Entomol 122:497-500

Shimoda T, Kagawa Y, Yoshizawa H, Nakano A, Matsuhira K, Yanagita H, Shimomoto M, Adachi-H T, Mori K, Hinomoto N, Hiraoka T, Nakajima T (2019) Moisturized sheltered sachets are potentially useful for the efficient release of selected predators in a wide range of humidity environments. BioControl 64:65-75

Shipp JL, Ward KI, Gillespie TJ (1996) Influence of temperature and vapor pressure deficit on the rate of predation by the predatory mite, Amblyseius cucumeris, on Frankliniella occidentalis. Entomol Exp Appl 78:31-38

Shipp L, Johansen N, Vanninen I, Jocobson R (2009) Greenhouse climate: an important consideration when developing pest management programs for greenhouse crops. Acta Hortic (ISHS) 893:133-143

Southwood TRE, May RM, Hassell MP, Conway GR (1974) Ecological strategies and population parameters. Am Nat 108:791-804

Stenseth C (1979) Effect of temperature and humidity on the development of Phytoseiulus persimilis and its ability to regulate populations of Tetranychus urticae (Acarina: Phytoseiidae, Tetranychidae). Entomophaga 24:311-317

Swift FC, Blaustein L (1980) Humidity tolerances of 3 species of phytoseiid mites (Acarina: Phytoseiidae). J N Y Entomol Soc 88:77

Toyoshima S, Amano H (1998) Effect of prey density on sex ratio of two predacious mites, Phytoseiulus persimilis and Amblyseius womersleyi (Acari: Phytoseiidae). Exp Appl Acarol 22:709-723

Tuda M (2011) Evolutionary diversification of bruchine beetles: climate-dependent traits and development associated with pest status. Bull Entomol Res 101:415-422

Tuda M, Ronn J, Buranapanichpan S, Wasano N, Arnqvist G (2006) Evolutionary diversification of the bean beetle genus Callosobruchus (Coleoptera: Bruchidae): traits associated with stored-product pest status. Mol Ecol 15:35413551

Ustchekow AT, Begljarow GA (1968) Effect of the temperature and humidity on the development of predatory mite Phytoseiulus persimilis A.-H. Proceedings of the XIII ${ }^{\text {th }}$ congress of entomology Moskva 198-199

Walzer A, Castagnoli M, Simoni S (2007) Intraspecific variation in humidity susceptibility of the predatory mite Neoseiulus californicus: survival, development and reproduction. Biol Control 41:42-52

Wharton GW (1985) Water balance of insects. In comprehensive insect physiology, biochemistry and pharmacology, Vol. 4, G.A. Kerkut and L.I. Gilbert (eds), Pergamon Press, Oxford. pp 565-603

Wharton GW, Devine TL (1968) Exchange of water between a mite Laelaps echidnina and the surrounding air under equilibrium conditions. J Insect Physiol 14:1303-1318

Wigglesworth VB (1942) The principles of insect physiology. $2^{\text {nd }}$ edit. London, pp 373-406

Williams MEDC, Kravar-Garde L, Fenlon JS, Sunderland KD (2004) Phytoseiid mites in protected crops: the effect of humidity and food availability on egg hatch and adult life span of Iphiseius degenerans, Neoseiulus cucumeris, N. californicus and Phytoseiulus persimilis (Acari: Phytoseiidae). Exp Appl Acarol 32:1-13

Winston PW, Bates DH (1960) Saturated solutions for the control of humidity in biological research. Ecology 41:232237 
Yoder JA (1998) A comparison of the water balance characteristics of Typhlodromus occidentalis and Amblyseius finlandicus mites (Acari: Phytoseiidae) and evidence for the site of water vapour uptake. Exp Appl Acarol 22:279286

Yousef AA, El-Keifl AH, Metwally AM (1982) Effect of temperature and photoperiod on the development, fecundity and longevity of Amblyseius swirskii Ath.-Henr. (Acari, Gamasida, Phytoseiidae). Anz Schadlingskde Pflanzenschutz Umweltschutz 55:107-109 
Table 1 Egg-adult developmental duration and adult longevity (mean $\pm \mathrm{SE}$ ) (days) of Amblyseius swirskii at different relative humidities (RHs) and water availabilities.

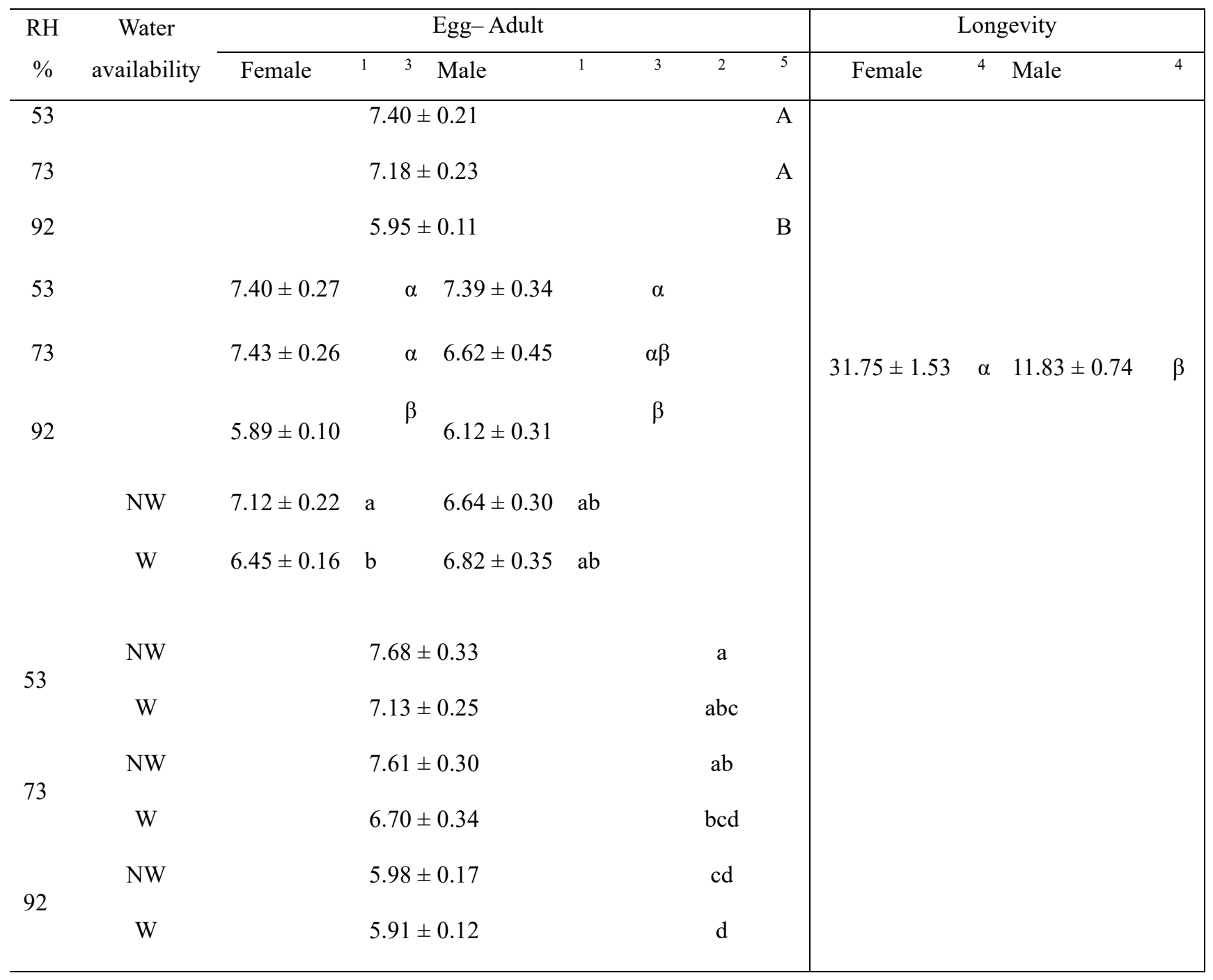

NW: no water, W: with water, Significance at $P=0.05$.

1 Same letters indicate no significant differences in multiple comparisons for the interaction between sexes and water availability for egg-adult stage.

2 Same letters indicate no significant differences in multiple comparisons for the interaction between RH and water availability for egg-adult stage.

3 Same Greek letters indicate no significant differences in multiple comparisons for the interaction between RH and sexes for egg-adult stage.

${ }^{4}$ Same Greek letters indicate no significant differences between females and males for adult longevity.

${ }^{5}$ Same uppercase letters indicate no significant differences between RHs for egg-adult stage. 


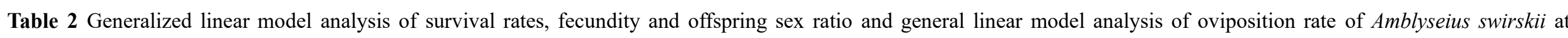
different levels of relative humidity $(\mathrm{RH})$ and water availability

\begin{tabular}{|c|c|c|c|c|c|c|c|c|c|c|c|c|c|c|c|c|c|c|c|c|c|}
\hline \multirow{2}{*}{ Sources } & \multicolumn{3}{|c|}{ Larval survival rate } & \multicolumn{3}{|c|}{$\begin{array}{l}\text { Protonymph survival } \\
\text { rate }\end{array}$} & \multicolumn{3}{|c|}{$\begin{array}{l}\text { Deutonymph } \\
\text { survival rate }\end{array}$} & \multicolumn{3}{|c|}{$\begin{array}{l}\text { Egg-adult survival } \\
\text { rate }\end{array}$} & \multicolumn{3}{|c|}{ Fecundity } & \multicolumn{3}{|c|}{ Oviposition rate } & \multicolumn{3}{|c|}{$\begin{array}{c}\text { Female offspring } \\
\text { ratio }\end{array}$} \\
\hline & $\mathrm{df}$ & $\chi^{2}$ & $P$ & $\mathrm{df}$ & $\chi^{2}$ & $P$ & $\mathrm{df}$ & $\chi^{2}$ & $P$ & $\mathrm{df}$ & $\chi^{2}$ & $P$ & df & $\chi^{2}$ & $P$ & df & $F$ & $P$ & $\mathrm{df}$ & $\chi^{2}$ & $P$ \\
\hline $\mathrm{RH}$ & 2 & 0.44 & 0.803 & 2 & 0.55 & 0.762 & 2 & 5.66 & 0.059 & 2 & 2.04 & 0.360 & 2 & 12.76 & 0.002 & 2,81 & 43.81 & $<.0001$ & 2 & 9.01 & 0.011 \\
\hline Water availability & 1 & 9.63 & 0.002 & 1 & 12.42 & 0.0004 & 1 & 0.94 & 0.332 & 1 & 24.20 & $<.0001$ & 1 & 18.04 & $<.0001$ & 1,81 & 66.08 & $<.0001$ & 1 & 0.12 & 0.734 \\
\hline $\mathrm{RH} \times$ water availability & 2 & 0.85 & 0.655 & 2 & 0.48 & 0.788 & 2 & 3.32 & 0.190 & 2 & 0.06 & 0.969 & 2 & 7.68 & 0.022 & 2,81 & 1.70 & 0.188 & 2 & 0.40 & 0.819 \\
\hline
\end{tabular}


Table 3 Life table parameters (bootstrap mean \pm SE) of Amblyseius swirskii at different levels of relative humidity (RH) with no water (NW) and with water (W)

\begin{tabular}{lccccccc}
\hline \multirow{2}{*}{ Parameters } & $33 \%$ & \multicolumn{2}{c}{$53 \% \mathrm{RH}$} & \multicolumn{2}{c}{$73 \% \mathrm{RH}$} & \multicolumn{2}{c}{$92 \% \mathrm{RH}$} \\
\cline { 5 - 8 } & $\mathrm{RH}$ & $\mathrm{NW}$ & $\mathrm{W}$ & $\mathrm{NW}$ & $\mathrm{W}$ & $\mathrm{NW}$ & $\mathrm{W}$ \\
\hline Number of females & 0 & 12 & 13 & 18 & 11 & 18 & 15 \\
Net reproductive rate $\left(R_{0}\right)$ & 0.00 & $2.54 \pm$ & $11.52 \pm$ & $5.78 \pm$ & $11.32 \pm$ & $8.26 \pm$ & $14.48 \pm$ \\
& & $0.71 \mathrm{~d}$ & $2.62 \mathrm{ab}$ & $1.25 \mathrm{c}$ & $3.10 \mathrm{abc}$ & $1.88 \mathrm{bc}$ & $2.44 \mathrm{a}$ \\
\hline Intrinsic rate of increase $(r)$ & 0.000 & $0.045 \pm$ & $0.150 \pm$ & $0.097 \pm$ & $0.159 \pm$ & $0.153 \pm$ & $0.236 \pm$ \\
& & $0.015 \mathrm{~d}$ & $0.017 \mathrm{~b}$ & $0.013 \mathrm{c}$ & $0.023 \mathrm{~b}$ & $0.018 \mathrm{~b}$ & $0.019 \mathrm{a}$ \\
\hline Finite rate of increase $(\lambda)$ & 0.00 & $1.05 \pm$ & $1.16 \pm$ & $1.10 \pm$ & $1.17 \pm$ & $1.17 \pm$ & $1.27 \pm$ \\
& & $0.02 \mathrm{~d}$ & $0.02 \mathrm{~b}$ & $0.01 \mathrm{c}$ & $0.03 \mathrm{~b}$ & $0.02 \mathrm{~b}$ & $0.02 \mathrm{a}$ \\
\hline Mean generation time (T), (d) & $\mathrm{NA}$ & $20.92 \pm$ & $16.30 \pm$ & $18.05 \pm$ & $15.30 \pm$ & $13.79 \pm$ & $11.34 \pm$ \\
& & $2.01 \mathrm{a}$ & $0.79 \mathrm{bc}$ & $1.02 \mathrm{ab}$ & $0.70 \mathrm{~cd}$ & $0.91 \mathrm{~d}$ & $0.40 \mathrm{e}$ \\
\hline Gross reproduction rate $(\mathrm{GRR})$ & 0.00 & $9.89 \pm$ & $17.84 \pm$ & $15.97 \pm$ & $17.37 \pm$ & $20.91 \pm$ & $18.88 \pm$ \\
& & $1.27 \mathrm{~b}$ & $2.80 \mathrm{a}$ & $2.18 \mathrm{a}$ & $3.79 \mathrm{ab}$ & $3.55 \mathrm{a}$ & $2.33 \mathrm{a}$ \\
\hline
\end{tabular}

The means followed by same letters in the same row are not significantly different according to the paired bootstrap test based on the confidence interval of differences at the $5 \%$ level.

NA: not available. 
Table 4 Comparison of $r$ values of Amblyseius swirskii when fed different types of food and reared under different temperature, relative humidity $(\mathrm{RH})$ and water availability conditions

\begin{tabular}{|c|c|c|c|c|c|}
\hline Food sources & $r$ & Temperature & $\mathrm{RH}$ & $\begin{array}{l}\text { Water } \\
\text { availability }\end{array}$ & References \\
\hline $\begin{array}{l}\text { Two-spotted spider mite, } \\
\text { T. urticae }\end{array}$ & 0.167 & $26^{\circ} \mathrm{C}$ & $70 \%$ & Yes & $\begin{array}{l}\text { El-Laithy and Fouly } \\
\text { (1992) }\end{array}$ \\
\hline Whitefly, B. tabaci & $\begin{array}{l}0.208 \text { and } 0.213 \text { for } \\
\text { different strains }\end{array}$ & $25^{\circ} \mathrm{C}$ & $60 \%$ & Yes & Nomikou et al. (2001) \\
\hline $\begin{array}{l}\text { Tomato russet mite, Aculops } \\
\text { lycopersici }\end{array}$ & 0.235 & $28^{\circ} \mathrm{C}$ & $75 \%$ & Yes & $\begin{array}{l}\text { Momen and Abdel- } \\
\text { Khalek (2008) }\end{array}$ \\
\hline A. lycopersici & 0.201 & $25^{\circ} \mathrm{C}$ & $70 \%$ & Yes & Park et al. (2011) \\
\hline Cattail pollen, Typha latifolia & 0.185 & $25^{\circ} \mathrm{C}$ & $70 \%$ & Yes & \\
\hline \multirow[t]{9}{*}{ T. latifolia } & 0 & $13{ }^{\circ} \mathrm{C}$ & $60 \%$ & Yes & \multirow{9}{*}{$\begin{array}{l}\text { Lee and Gillespie } \\
(2011)\end{array}$} \\
\hline & -0.002 & $15^{\circ} \mathrm{C}$ & $60 \%$ & Yes & \\
\hline & 0.016 & $18^{\circ} \mathrm{C}$ & $60 \%$ & Yes & \\
\hline & 0.076 & $20^{\circ} \mathrm{C}$ & $60 \%$ & Yes & \\
\hline & 0.135 & $25^{\circ} \mathrm{C}$ & $60 \%$ & Yes & \\
\hline & 0.145 & $30^{\circ} \mathrm{C}$ & $60 \%$ & Yes & \\
\hline & 0.160 & $32{ }^{\circ} \mathrm{C}$ & $60 \%$ & Yes & \\
\hline & 0.134 & $34{ }^{\circ} \mathrm{C}$ & $60 \%$ & Yes & \\
\hline & 0.067 & $36^{\circ} \mathrm{C}$ & $60 \%$ & Yes & \\
\hline Dried fruit mite, $C$. lactis & 0.175 & $23^{\circ} \mathrm{C}$ & $65 \%$ & Yes & \multirow[t]{4}{*}{ Nguyen et al. (2013) } \\
\hline Cattail pollen & 0.158 & $23{ }^{\circ} \mathrm{C}$ & $65 \%$ & Yes & \\
\hline Artificial diet 1 & 0.104 & $23^{\circ} \mathrm{C}$ & $65 \%$ & Yes & \\
\hline Artificial diet 2 & 0.181 & $23{ }^{\circ} \mathrm{C}$ & $65 \%$ & Yes & \\
\hline Panonychus citri & 0.165 & $25^{\circ} \mathrm{C}$ & $80 \%$ & Yes & Ji et al. (2013) \\
\hline Suidasia medanensis & 0.222 & $25^{\circ} \mathrm{C}$ & $70 \%$ & Yes & $\begin{array}{l}\text { Midthassel et al. } \\
(2013)\end{array}$ \\
\hline T. urticae & 0.134 & $25^{\circ} \mathrm{C}$ & $65 \%$ & Yes & \multirow[t]{7}{*}{ Riahi et al. (2017) } \\
\hline Almond pollen & 0.180 & $25^{\circ} \mathrm{C}$ & $65 \%$ & Yes & \\
\hline Bee pollen & -0.101 & $25^{\circ} \mathrm{C}$ & $65 \%$ & Yes & \\
\hline Date pollen & 0.080 & $25^{\circ} \mathrm{C}$ & $65 \%$ & Yes & \\
\hline Almond pollen $+T$. urticae & 0.175 & $25^{\circ} \mathrm{C}$ & $65 \%$ & Yes & \\
\hline Bee pollen $+T$. urticae & 0.129 & $25^{\circ} \mathrm{C}$ & $65 \%$ & Yes & \\
\hline Date pollen $+T$. urticae & 0.142 & $25^{\circ} \mathrm{C}$ & $65 \%$ & Yes & \\
\hline Cenopalpus irani & 0.140 & $25^{\circ} \mathrm{C}$ & $60 \%$ & Yes & \multirow[t]{2}{*}{ Bazgir et al. (2018) } \\
\hline Eotetranychus frosti & 0.179 & $25^{\circ} \mathrm{C}$ & $60 \%$ & Yes & \\
\hline \multirow[t]{7}{*}{ C. lactis } & 0.000 & $25^{\circ} \mathrm{C}$ & $33 \%$ & No/yes & \multirow[t]{7}{*}{ This study (Table 3) } \\
\hline & 0.045 & $25^{\circ} \mathrm{C}$ & $53 \%$ & No & \\
\hline & 0.097 & $25^{\circ} \mathrm{C}$ & $73 \%$ & No & \\
\hline & 0.153 & $25^{\circ} \mathrm{C}$ & $92 \%$ & No & \\
\hline & 0.150 & $25^{\circ} \mathrm{C}$ & $53 \%$ & Yes & \\
\hline & 0.159 & $25^{\circ} \mathrm{C}$ & $73 \%$ & Yes & \\
\hline & 0.236 & $25^{\circ} \mathrm{C}$ & $92 \%$ & Yes & \\
\hline
\end{tabular}




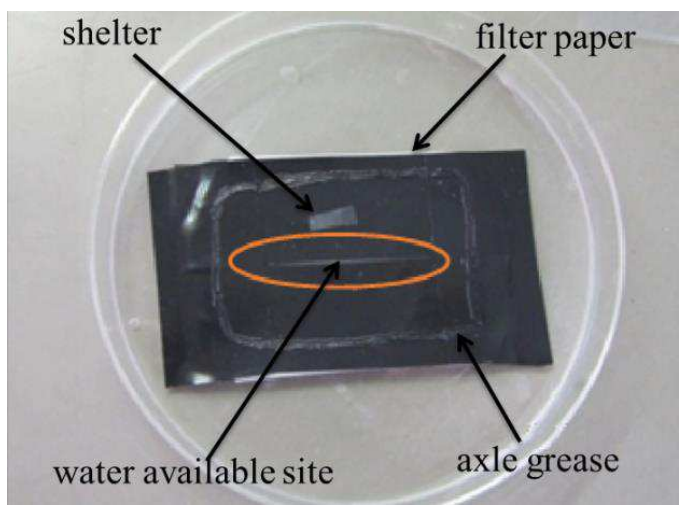

Fig. 1 A plate inside a petri dish for rearing Amblyseius swirskii.

(a)

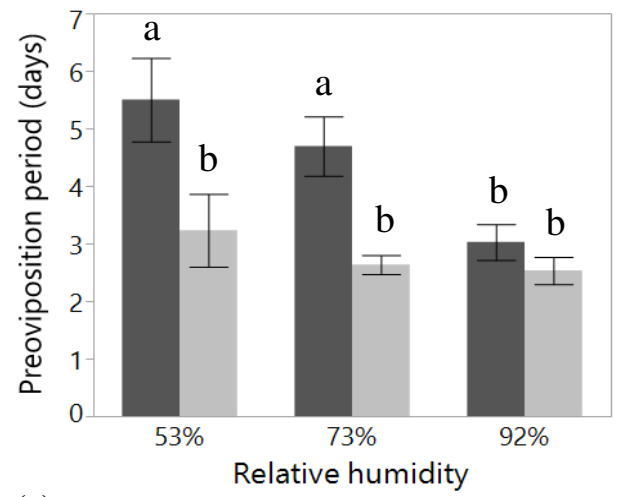

(c)

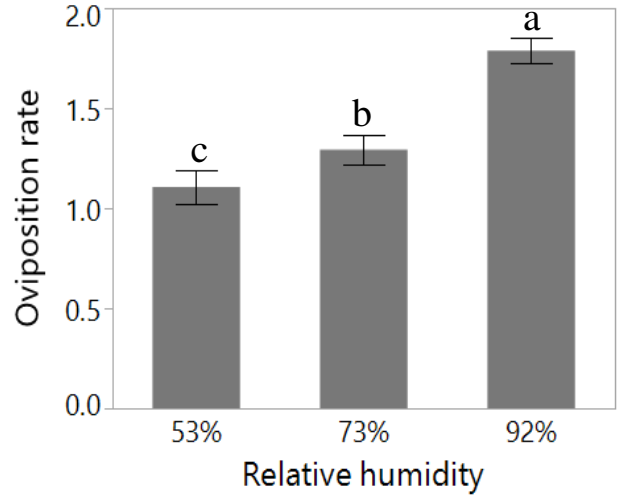

(b)

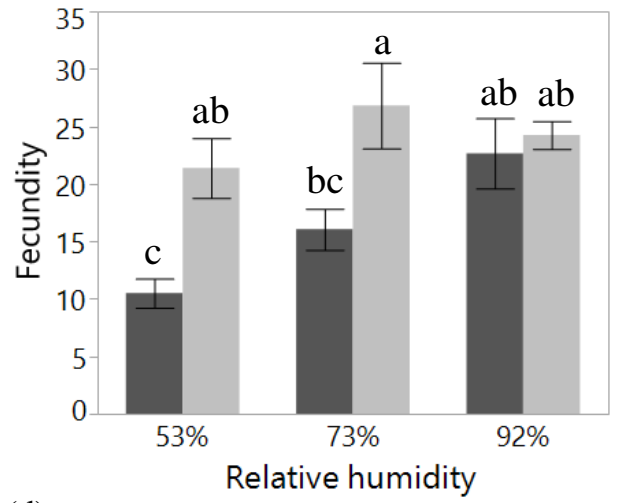

(d)

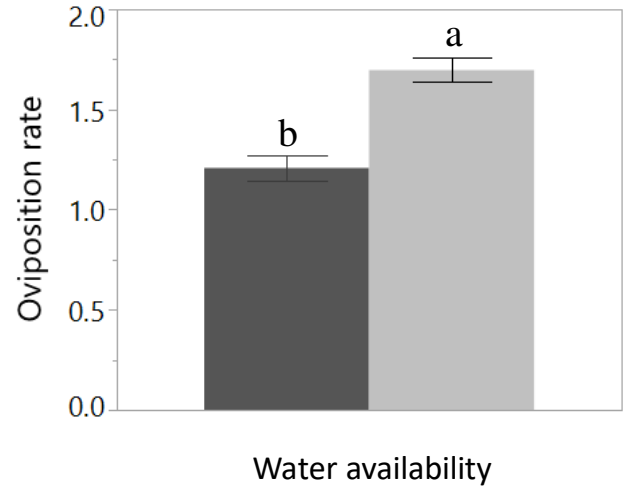

Fig. 2 Reproduction parameters of Amblyseius swirskii in response to relative humidity (RH) and water availability. (a) Preoviposition period, (b) fecundity and (c, d) oviposition rate per day. Black, no water; light gray, with water. Mean \pm SE. Same letters indicate no significant differences at $P=0.05$. For significant interaction effects, all pairwise combinations of two factors are compared and shown. Only significant results are presented. 

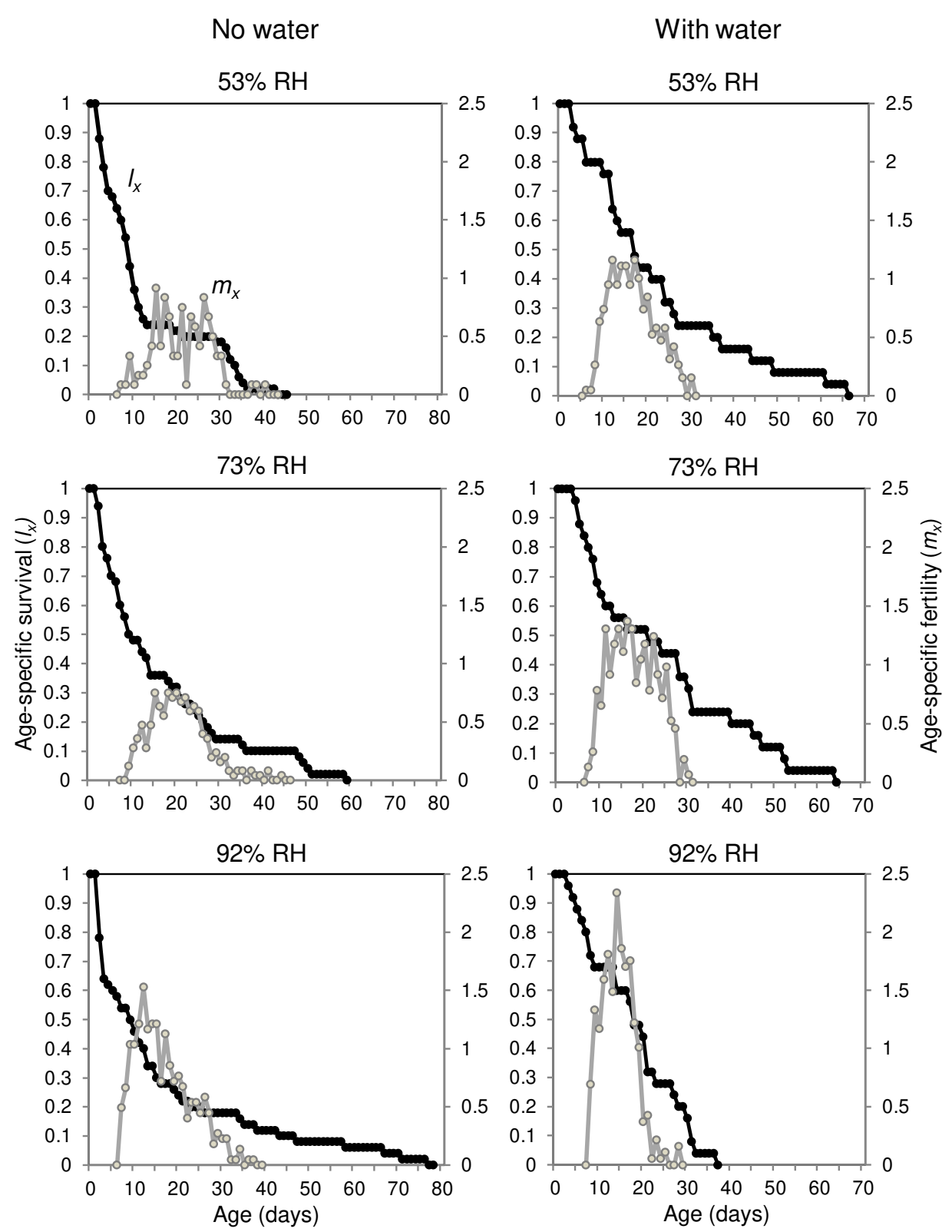

Fig. 3 Age-specific survival $\left(l_{x}\right)$ and age-specific fertility $\left(m_{x}\right)$ of Amblyseius swirskii at different levels of relative humidity $(\mathrm{RH})$ and water availability. Black, $l_{x}$; gray, $m_{x}$. 


\section{Figures}

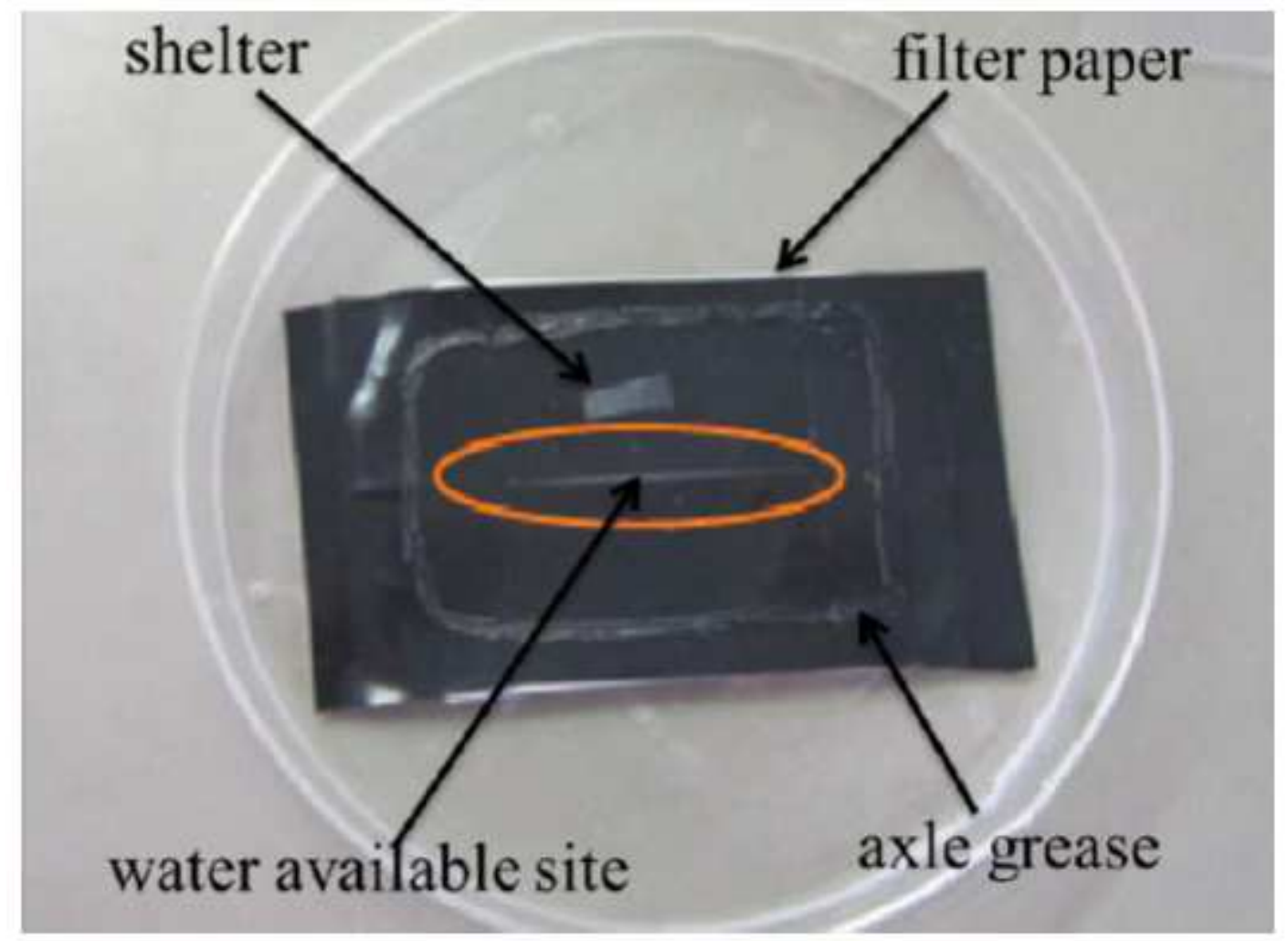

Figure 1

A plate inside a petri dish for rearing Amblyseius swirskii. 
(a)

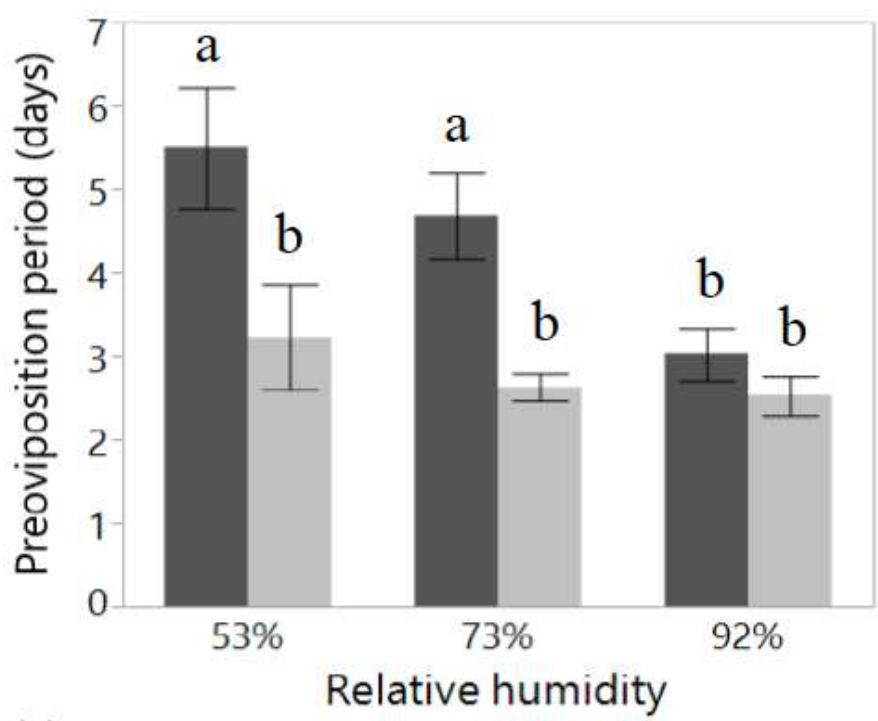

(c)

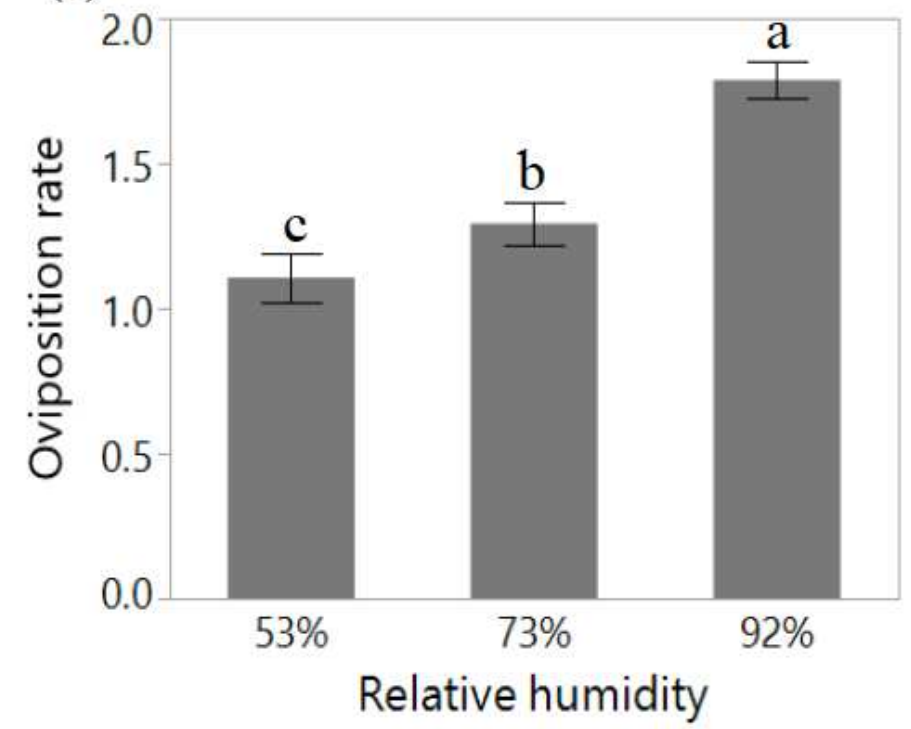

(b)

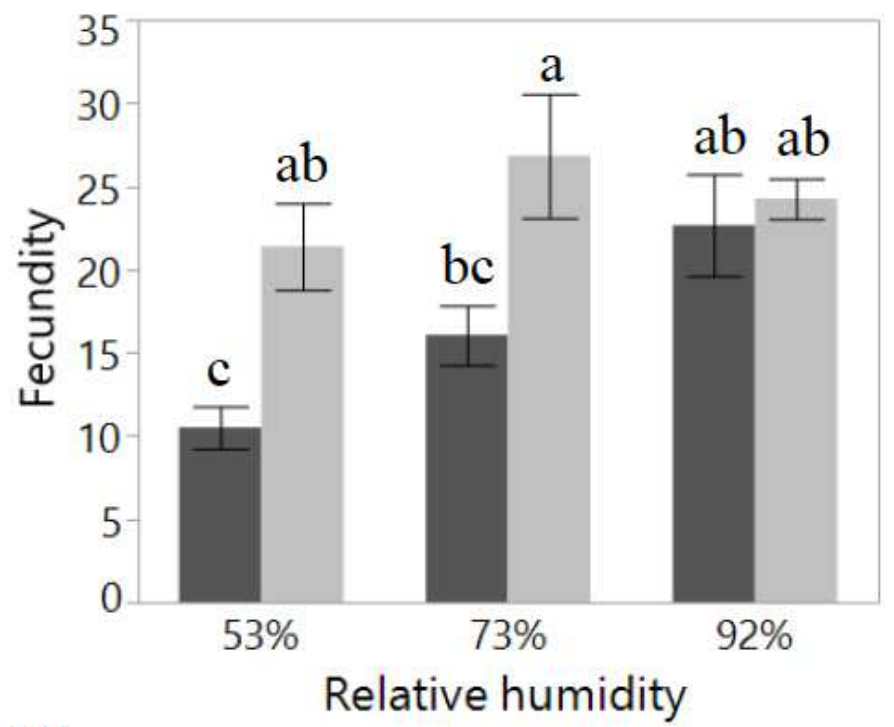

(d)

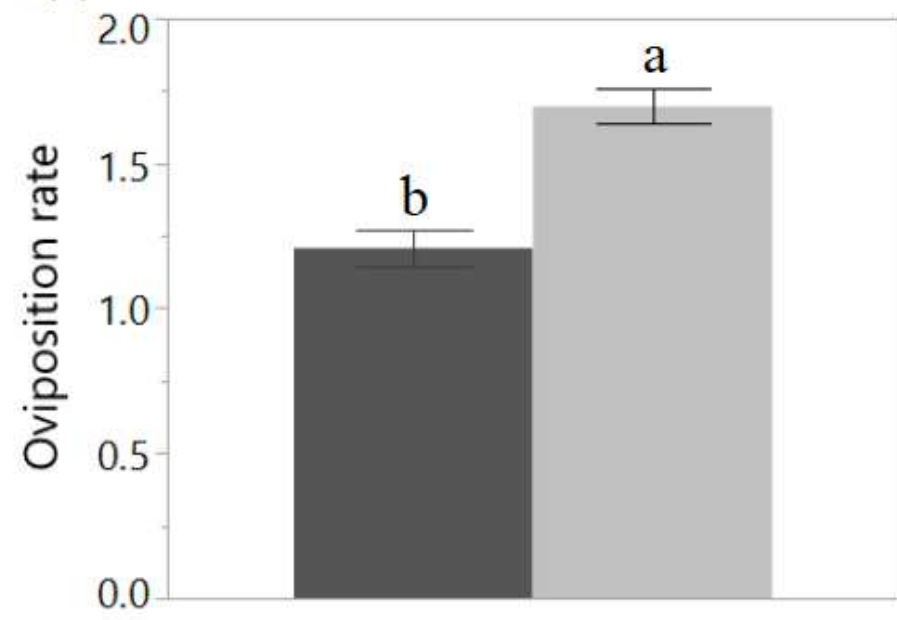

Water availability

\section{Figure 2}

Reproduction parameters of Amblyseius swirskii in response to relative humidity $(\mathrm{RH})$ and water availability. (a) Preoviposition period, (b) fecundity and (c, d) oviposition rate per day. Black, no water; light gray, with water. Mean \pm SE. Same letters indicate no significant differences at $P=0.05$. For significant interaction effects, all pairwise combinations of two factors are compared and shown. Only significant results are presented. 
No water

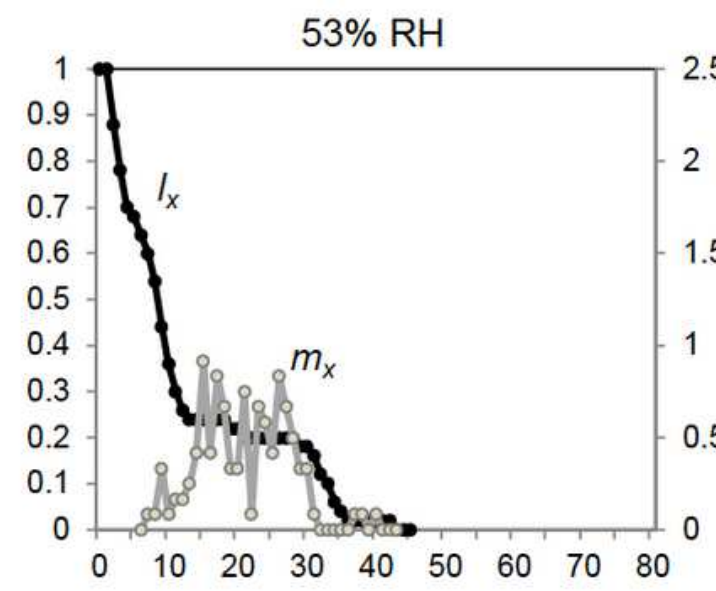

$73 \% \mathrm{RH}$
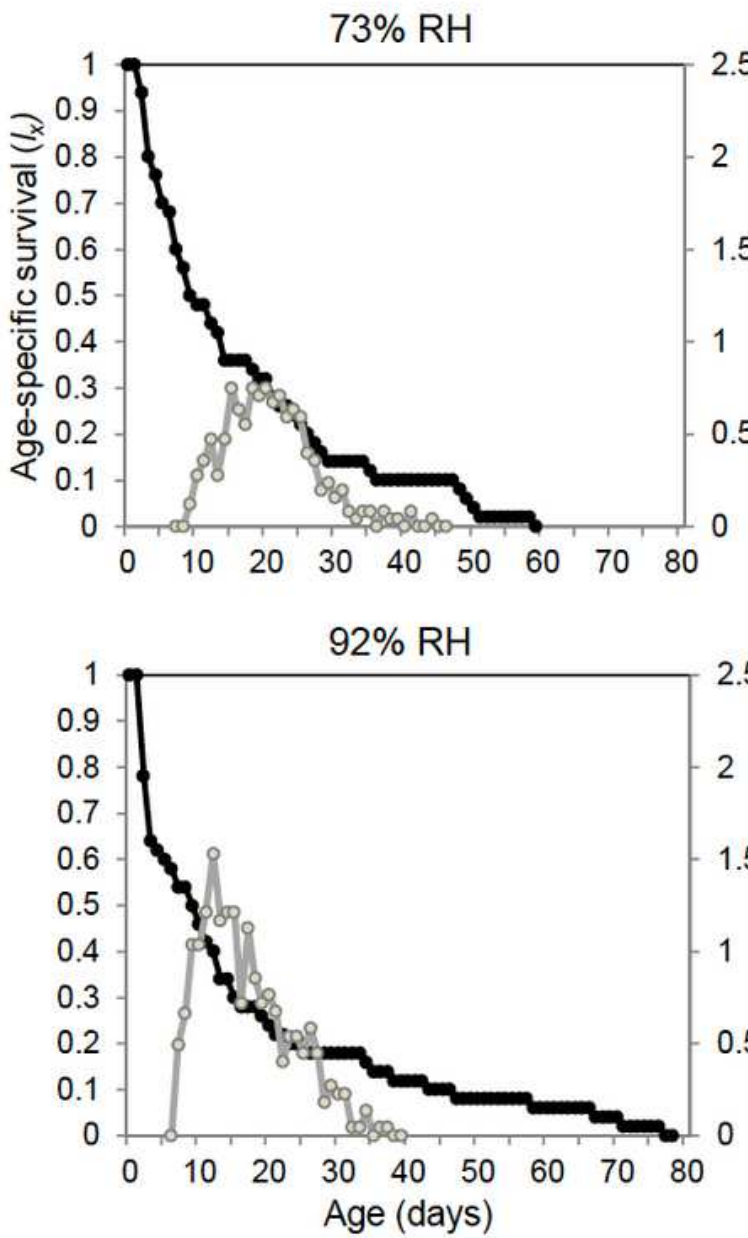

With water
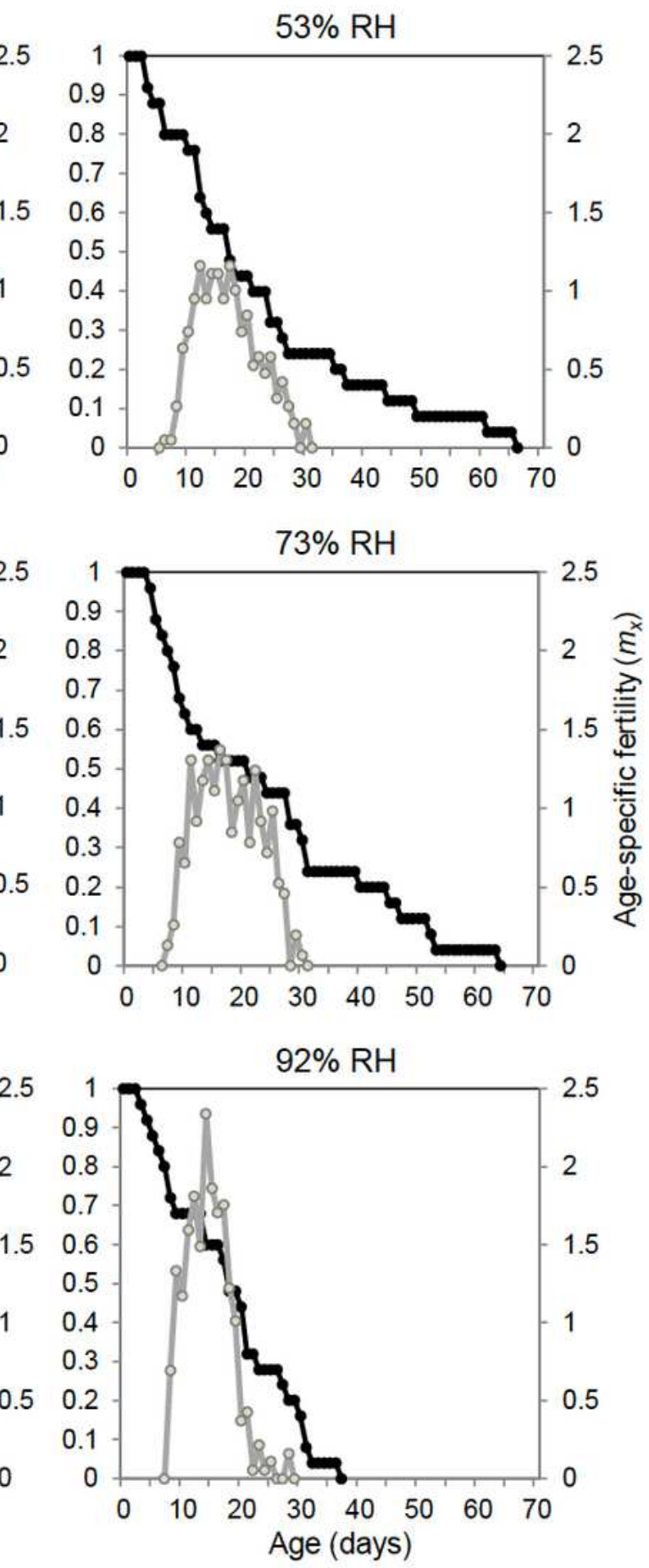

Figure 3

Age-specific survival (Ix) and age-specific fertility $(\mathrm{mx})$ of Amblyseius swirskii at different levels of relative humidity $(\mathrm{RH})$ and water availability. Black, Ix; gray, $\mathrm{mx}$.

\section{Supplementary Files}


This is a list of supplementary files associated with this preprint. Click to download.

- SuppltablesS12swirskiihumidityBioContpreprint.docx 